\title{
A MORTE IMPOSSÍVEL: uma análise da luta de vida e morte na figura do senhor e do servo*
}

\author{
Maria de Lourdes Borges
}

SÍNTESE - Este artigo propõe-se a determinar o sentido da morte na figura do senhor e do servo da Fenomenologia do Espirito de Hegel. Para tal propósito, o texto será dividido em três partes. Na primeira, exporei o pano de fundo no qual se encontra a figura - a seção "Autoconsciência da Fenomenologia do Espírito bem como a importância desta no desenvolvimento da obra em questão. Num segundo momento, exporei o desenvolvimento da figura numa análise interna de sua estrutura, ressaltando o papel que aí cumpre a luta de vida e morte. Por fim, farei uma analogia entre a figura e a História, mais especificamente, com o período do Terror da Revolução Francesa.

ABSTRACT - This article, divided into three parts, intends to clarify the sense of death of the sir and the servant of the logical phenomenon of Hegel's spirit. In the first part, I carefully examined the auto consciousness of the logical phenomenon of the spirit as well as its importance for the development of this piece. In the second part. I thoroughly examined its development based on an internal analysis of its structure, vhith emphasis on the fight for life and death. In the third part, I compared this analysis with History, especially with the horror of the French Revolution.

\section{1 - Da consciência à autoconsciência: a emergência da alteridade}

Qual o significado da figura do senhor/servo? Para responder a esta pergunta devemos fazer preliminarmente algumas considerações sobre o seu locus dentro da obra hegeliana: a seção "Autoconsciência" da Fenomenologia do Espirito. Comecemos, pois, com a obra em questão. Pode-se dizer que a Fenomenologia é uma sucessão, teleologicamente orientada, daquilo que Hegel denominou "experiência da consciência": a estadia em cada um dos degraus do paciente percurso do Espírito do mundo na civilização. Se na seção "Espírito" a consciência entra em contato com os momentos mais significativos do fazer racional dos homens na História, as seções anteriores, nos diz Hegel, são abstrações deste mesmo fazer: "O Espirito é, então, a essência absoluta e real que se sustenta a si mesmo. Todas as figuras anteriores são abstrações deste Espírito. Nelas ele se analisa, distingue seus próprios momentos e demora-se nos momentos singulares. Esta ação de isolar tais momentos pressupõe o Espírito e subsiste nele, ou ela existe somente no Espírito que é existência"."

O Espírito é, portanto, o todo, a existência. Os momentos enfocados anteriormente à seção "Espírito" têm no Espírito mesmo seu substrato e não são sem ele. Cada se-

- Este artigo foi baseado na dissertação de mestrado da autora, intitulada Os jogos da alteridade, defendida na UFRGS em março de 1990.

1 HEGEL, Phänomenologie des Geistes (Ph. G.), Werke in zwanzig Bänden, Moldenhauer/Michel, Frankfurt, Suhrkamp Verlag, p. 325.

\begin{tabular}{|l|l|l|l|l|l|}
\hline VERITAS & Porto Alegre & v. 40 & $\mathrm{n}^{2} 157$ & Março 1995 & p. 37-48 \\
\hline
\end{tabular}


ção, no entanto, não nos dá separadamente a totalidade do Espírito, cada uma o apresenta sob um aspecto especifico.

A seção "Consciência" marca os momentos mais simples e parciais do Espírito, nos quais é referido um tipo de relação da consciência com seu mundo, caracterizado por um acesso passivo a este. O mundo chega à consciência enquanto o portador da verdade, que cabe a ela apenas acolher. Nesta seção, a consciência não sabe que é igualmente importante neste processo, pois ela não se concebe ainda como a que conhece. Isto é dado apenas na seção "Autoconsciência", onde é mostrada a constituição daquilo que é a marca da Filosofia moderna - de Descartes ao próprio idealismo alemão: o Eu pensante, autônomo, livre e doador de regras, do qual depende, em última instância, todo e qualquer conhecimento do mundo.

Hegel explicita, já no início do texto "Independência e dependência da autoconsciência; dominação e servidão", a condição necessária para que haja autoconsciência: "a autoconsciência é em si e para si, enquanto e devido ao fato de que ela é em si e para si para uma outra, isto é, ela só é enquanto reconhecida". ${ }^{2}$ A autoconsciência só é verdadeira, livre e autônoma se for reconhecida por outra autoconsciência. Não há, pois, autoconsciência sozinha, ou, dito de outra forma, não há sujeito autônomo que não se encontre numa trama de relações entre sujeitos.

A seção "Autoconsciência" não expressa ainda esta trama de relações intersubjetivas, sendo, entretanto, o momento lógico necessário para que tal seja possível, o que ocorrerá apenas mais tarde na seção "Espirito". Esta relação entre a constituição da autoconsciência e seu pano de fundo, o Espírito, é assim exposta por Hegel: "Assim, já existe para nós o conceito de Espírito. $O$ que virá depois para a consciência é a experiência do que é o Espírito, esta substância absoluta que, na perfeita liberdade e independência dos seus contrários, isto é, de diferentes consciências de si sendo para si, constitui a unidade: um Eu que é um Nós e um Nós que é um Eu". ${ }^{3}$

Nesta passagem, Hegel nos dá uma definição de Espírito: uma substância que se constitui enquanto unidade de várias consciências de si, uma substância composta da multiplicidade de individualidades. Poder-se-ia dizer, de outra forma, que o que aqui está em jogo é a formação do corpo social. Na seção "Autoconsciência", todavia, não há ainda esta experiência para a consciência; neste sentido, o social não é aqui narrado, podendo ser considerado como o todo do qual as experiências são abstraídas. Trata-se, então, de uma abstração do social, do ponto de vista das estruturas da consciência individual. Este é, entretanto, apenas um nível da Fenomenologia. Podemos dizer que, para nós, que assistimos o percurso paciente do Espírito no decorrer da civilização ocidental, trata-se de abstrair deste percurso as relações da consciência com seu outro e olhar detidamente os impasses da alteridade que necessitam ser resolvidos para a constituição do social.

Temos, por outro lado, um percurso diverso, da consciência mesma que, não tendo o social como pressuposto, deve percorrer um caminho para obtê-lo. Neste sentido, os impasses da seção "Autoconsciência" advêm da atividade exploratória da consciência frente à alteridade e a resolução destes impasses é condição de possibilidade para que o sujeito da experiência fenomenológica passe da primeira pessoa do singular (Eu) para a primeira pessoa do plural (Nós). Deve-se indagar qual a razão da necessidade desta passagem. Por que o Nós necessita ser constituido?

2 Ph. G., p. 145.

3 Ph. G., p. 145. 
Hegel nos diz na Fenomenologia que o "verdadeiro é o todo" e que este verdadeiro, enquanto absoluto, "só é no fim o que ele é na verdade". ${ }^{4}$ Logo, a possibilidade de expressão do verdadeiro pela consciência só pode se dar ao final do processo, ou seja, no saber absoluto. Os processos que se davam anteriormente, na seção "Consciência", fazem parte de um tipo de acesso ao mundo no qual a possibilidade de expressão desta verdade é limitada. É necessário passar a um estágio onde a autoconsciência acompanhe toda a expressão da verdade, autoconsciência esta que poderia ser expressa, na linguagem kantiana, como "o veículo de todos os conceitos em geral".

O que se lê no inicio do capítulo "Independência e dependência da autoconsciência" é que aquilo que se apresenta como possibilidade de todos os juízos - a autoconsciência - tem também um pressuposto - uma outra autoconsciência. Em suma, só há conhecimento se houver reconhecimento. Não há, portanto, segundo Hegel, verdade que possa ser enunciada a partir apenas de dois elementos: uma autoconsciência e um mundo. Só há verdade se houver outra autoconsciência que reconheça a primeira como a portadora de um saber sobre o mundo.

Todavia, a verdade que é obtida ao final do percurso da Fenomenologia não abarca apenas o conhecimento do mundo. Ella é resultado também da ação da consciência sobre este mundo. É na seção "Autoconsciência" que o universo da razão prática começa a ser explorado. Aí, o mundo se apresenta, não apenas como o que deve ser conhecido, mas também como aquilo que deve ser formado pela consciência e construido enquanto uma realidade social e política. Neste sentido, podemos dizer que os embates entre as consciências que vemos já no início desta seção, na figura do senhor e do servo, representam, neste nivel de abstração, os impasses da constituição de uma comunidade política, onde o homem deixa para trás sua vida imediata e vem a ser racional.

\section{2-A estrutura da figura e o lugar da morte}

O capitulo "Independência e dependência da autoconsciência", no qual se encontra a figura do senhor e do servo, apresenta três partes: a exposiç‘ão da lógica pura do reconhecimento, a experiência fenomenológica do reconhecimento e a relação entre 0 senhor e o servo como advinda da experiência fenomenológica do reconhecimento.

A primeira parte trata de explicitar o que deve ser entendido por reconhecimento, ou seja, a concepção de que a outra consciência é igual à primeira e que, portanto, - fazer das duas autoconsciências deve ser simétrico. Esta simetria está expressa na fórmula: "cada uma vê a outra fazer o mesmo que ela faz, cada uma faz ela mesma o que exige da outra, e faz o que faz contanto que a outra faça o mesıno" ${ }^{6}$ Esta perfeita simetria funciona no texto como uma "matriz lógica" do reconhecimento; todavia, a forma como o "puro conceito do reconhecimento" aparece para a autoconsciência conduzirá a uma assimetria: uma conseiência apenas reconhece, a outia apenas é reconhecida. É neste segundo momento do texto, de desequilíbrio entre as duas autoconsciências, que se dá a luta à morte. Ela é provocada pela "entradá em cena de um indivíduo frente a outro indivíduo". " A autoconsciência, que se conceibia enquanto senhora do mundo, necessita dividir seu senhorio com outra.

4 Ph. G., p. 24

5 KANT, Crítica da Razão Pura, B 399.

6 Ph. G., p. 146.

7 Ph. G., p. 148.

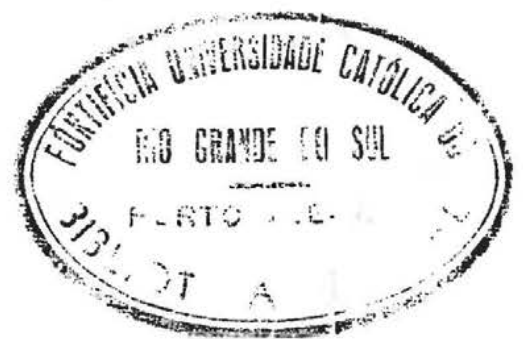


Qual a razão da luta à morte? Por que a outra consciência deve ser eliminada? Se há uma necessidade do processo de passagem do Eu ao Nós, por que o aparecimento de outra autoconsciência năo se dá, por assim dizer, "num clima da confraternização"?

A experiência fenomenológica do reconhecimento não apresenta as duas consciências imediatamente enquanto autoconsciências. Hegel nos diz que elas se apresentam uma para a outra "como objetos comuns", como figuras autônomas que, entretanto, só o são no "ser da vida". ${ }^{8}$ A outra deve ser, então, eliminada, pois através da outra ela se enfrenta com aquilo que ela mesma é: dependente da vida. Ela se quer como pura independência, como pura liberdade para a qual o mundo natural significa limitação. Assim, trata-se, para a autoconsciência, não apenas de excluir a outra, mas de livrar-se de sua própria vida naquilo que ela tem de natural. Para negar sua dependência do ser da vida e, ao mesmo tempo, tentar eliminar aquela que surge frente a ela como mergulhada na coisidade, a consciência põe em risco a sua vida e a da outra. É o elemento mesmo da vida que deve ser desprezado, é a independência do mundo natural o que é procurado através da busca da morte.

Se compreendemos a necessidade deste combate entre as duas consciências, ainda nos resta a seguinte questão: por que a luta de vida e morte não termina efetivamente na morte de uma das consciências? Ou, dito de outra forma, por que a morte não é uma solução? Kojève assinala bem este ponto ao mostrar que o central é o risco da vida que não leva, entretanto, à morte: "no texto em questão, ele [Hegel] diz expressamente que apenas o risco de vida é suficiente para realizar o ser humano. O ser que voluntariamente arriscou sua vida, mas escapou à morte, pode viver humanamente". ${ }^{9}$

A obtenção da morte seria um engodo, pois não levaria àquilo que a consciência procura: ser pura autoconsciência. A morte de uma autoconsciência seria a impossibilidade do reconhecimento e, sem reconhecimento, conforme nos é dito no início do texto, não há autoconsciência: a autoconsciência só é enquanto reconhecida. A morte de sua outra significa, portanto, sua impossibilidade de ser enquanto autoconsciência.

Através da morte, a consciência não atinge uma verdadeira autonomia. A morte de uma autoconsciência significaria uma impossibilidade da relação que deve estar presente no reconhecimento. A morte poderia ser a negação da vida imediata, da qual a consciência quer livrar-se a fim de atingir uma pura independência; entretanto, não há liberdade na morte, através dela as consciências concedem uma a outra, não a liberdade no seu sentido humano, mas uma independência feita de indiferença, como a das coisas. Da morte, nesta figura, deve-se dizer que é necessário o risco, mas impossivel sua efetivação.

Se a morte não é uma solução, por que nos é afirmada a importância do medo da morte, a ponto deste temor ser considerado o "início da sabedoria"? ${ }^{10}$ Por que a consciência que temeu a morte (o servo) é aquela que encontrará a verdadeira autonomia? Por que o senhor, que não teve medo, não vem a ser uma autoconsciência autônoma?

O servo éaquele que teve medo e desiste de levar a termo o combate. A razão do seu medo é a:consideração de que "a vida é tão importante quanto a autoconsciência

8 Ph. G., p. 148.

9 KOJĖVE, Introduction à la lecture de Hegel, Paris, Gallimard, 1947, p. 570.

10 Ph. G., p. 153. 
pura". ${ }^{11} \mathrm{O}$ medo da morte é, todavia, mais do que um medo de alguma coisa e, neste sentido, pode ser considerado como uma angústia em relação a todo seu ser. Da angústia do servo pode ser dito: "Esta consciência provou a angústia não desta ou daquela coisa, não durante tal ou qual instante, mas ela provou a angústia da integralidade de sua essência, pois ela sentiu o medo da morte, o senhor absoluto. Nesta angústia foi dissolvida intimamente, tremeu nas profundezas de si mesmo e tudo o que era fixo nela vacilou". ${ }^{12}$

O medo deste senhor absoluto, a morte, dissolve não apenas a ligação do servo com a coisidade mas também a própria relação de interdependência entre o senhor e o servo. Ao desligar o servo daquilo que o prendia ao mundo da vida, o medo é condição de possibilidade da emergência de uma consciência que supera a perspectiva, tanto do senhor, quanto do servo. O medo apresenta, pode-se dizer, uma função dupla. Num primeiro momento, é devido ao medo que uma consciência desiste do combate e decide se subordinar à outra; entretanto, è o mesmo medo que dissolve esta relação por fazer tremer toda a fixidez do servo que se encontrava preso à coisidade. 0 mesmo medo que inicialmente induz à servidão, num outro momento permitirá ao servo deixar de ser ele mesmo e aceder à condição de consciência universal.

E, como consciência universal, o servo trabalha a coisidade. Este trabalho, entretanto, vai além do trabalho material e indica, antecipando outros momentos da própria Fenomenologia, a resolução da dialética da autonomia: a constituição do mundo pelo homem, através da Cultura.

\section{3 - Morte e terror}

Pretendo fazer a seguir um paralelo entre a passagem sobre a morte na figura e um período determinado na História: o período do Terror da Revolução Francesa. Antes disso, é necessário esclarecer qual a possibilidade de transposição histórica das figuras da Fenomenologia.

As figuras da consciência e, por conseguinte, a figura do senhor e do servo são, como já foi dito, abstrações do Espíito. Neste sentido, elas não podem ser consideradas como narrativas de momentos históricos. Por outro lado, embora a ordem fenomenológica apresente os momentos da consciência como anteriores aos momentos do Espírito, dando a impressão de que estes derivam e encarnam as figuras da consciência, que fariam as vezes de estruturas lógicas fundamentais a serem completadas com um conteúdo histórico, o processo de gênese concreta (algo como a ordem das coisas e não da razão fenomenológica) é exatamente o inverso. É só a partir do percurso do Espírito, ou do desenvolvimento da História pelo homem, que se pode ter as figuras da consciência, que são, em última análise, esta evolução olhada e suspensa sob o ponto de vista da consciência individual, e esta só pode passar da consciência sensível ao saber absoluto porque é produto de uma época onde (segundo Hegel) a razão informa o mundo.

A dualidade da autoconsciência e o combate pelo reconhecimento que se expressará na figura do senhor/servo é, por sua vez, a expressão do processo de luta histórica pelo reconhecimento entre dois indivíduos que se vêem na sua igualdade e respeitam cada um a autonomia do outro. A formulação do reconhecimento, enquanto a necessidade de ver o outro como em si e para si (ou seja, na sua autonomia) só é possí-

11 Ph. G., p. 150.

12 Ph. G., p. 153. 
vel (a nível lógico e fenomenológico) porque se atingiu um patamar histórico informado pela idéia de igualdade.

A figura do senhor/servo representa a luta pelo reconhecimento. Ao tentar fazer um paralelo entre a figura e a História, devemos ter em mente que esta luta não se encontra apenas num lugar específico da História, ela perpassa como um fio condutor as experiências humanas de tentativa de constituição de uma sociedade baseada na igualdade entre os homens. Ao mesmo tempo, ela é descrita na Fenomenologia porque é o enfrentamento necessário para que o mundo tenha irrompido numa época onde reina a Razão. Para Hegel, esta época tem na Revolução Francesa um dos seus momentos essenciais. Neste sentido, a hipótese que desenvolverei, não negando o caráter universal desta figura, é que sua forma de articulação interna expressa bem os ideais desta última luta pelo reconhecimento, ou seja, os impasses da própria Revolução Francesa.

Uma das evidências que nos autoriza a levar adiante a analogia pretendida é a retomada por Hegel do medo do senhor absoluto, a morte, no capítulo da Fenomenologia intitulado "Liberdade absoluta e Terror", onde são referidas as experiências da consciência neste conturbado período da Revolução: "Estas las consciências singulares] que sentiram o temor do senhor absoluto, a morte, prestam-se novamente à negação e à diferença, se ordenam sob as massas, e se elas retornam a uma obra fracionada e limitada, elas retornam através disso à sua efetividade substancial". ${ }^{13}$

O mesmo medo do senhor absoluto aparece num e noutro momento. Na figura do senhor e do servo, o medo da morte impedia as consciências de levarem sua luta até a destruição, pois a morte não conduziria a nada além da impossibilidade do reconhecimento. No contexto do Terror acima citado, não se trata mais de duas consciências, mas de uma multiplicidade de consciências singulares - o corpo social - que se pretende dar uma ordenação. Esta ordenação aparece num primeiro momento como limitação; ela é, entretanto, o caminho que se afasta da destruição em direção à eticidade.

Aqui, por não se tratar mais da consciência particular e sim do Espírito, não é o servo como consciência singular, mas as consciências singulares que, no seu conjunto, a partir do medo da morte, tentam dar-se uma ordenação enquanto corpo social. O momento da vontade que se quer absolutamente livre passa a dar-se um conteúdo num Estado racional, com suas instituições que são, por sua vez, obra dos próprios indivíduos.

Pode-se afirmar que a luta de morte entre as duas autoconsciências e o período do Terror da Revolução Francesa guardam semelhanças no que se refere à vontade infinita que pretende a destruição de tudo que se lhe apresenta como limitação. Em ambas - na figura e nesta que se pode denominar sua última roupagem histórica - é o temor da morte que lhe concede a sabedoria de refrear a fúria do livre arbítrio. Rastreemos, pois, as semelhanças entre estes momentos.

No contexto da figura do senhor e do servo, a morte ocupa um papel contraditório. Por um lado, faz-se necessário arriscar a vida para que a consciência se liberte de sua naturalidade e afirme sua autonomia. Por outro lado, a morte de um dos combatentes leva à impossibilidade do reconhecimento. Conclui-se daí que a luta é necessária, mas que a morte enquanto princípio nos impossibilita atingir o fim pretendido. Deve-se arriscar a vida, sem colocar em risco a possibilidade do reconhecimento.

13 Ph. G., p. 438. 
Se fizermos a transposição da luta pelo reconhecimento entre duas autoconsciências para um contexto histórico onde a nova organização sócio-política tem como pilar básico a idéia de igualdade - a Revolução Francesa - pode-se dizer que esta dualidade da morte aí também se faz presente. Por um lado, faz-se necessário arriscar a vida na conquista mesmo de uma nova roupagem para o ser humano, que não é mais determinado pela sua naturalidade, pelo seu lugar social dado por nascimento. Arriscar a vida na luta levava as consciências a fazer perecer (e fluidificar) tudo o que era fixo. Da mesma forma, a Revolução Francesa torna nulas as formas de organização política anteriores.

Para Hegel, a passagem a uma nova sociedade fundada na liberdade e na igualdade entre os homens, na situação especifica da França, não poderia dar-se de forma pacífica, "Todo o sistema do Estado aparecia como uma única injustiça. A transformação não foi empreendida pelo governo. Ela não foi empreendida por ele porque a corte, o clero, a nobreza, os parlamentos mesmo não queriam renunciar à posse de seus privilégios, nem devido à miséria, nem pelo direito que é em si e para si. ${ }^{14}$

Através deste comentário, onde Hegel analisa a violência do inicio do processo revolucionário francês, pode-se constatar que nem toda violência deve ser condenada. Tratava-se aí de uma violência aceitável que não pretendia propor-se enquanto forma de governo, mas visava opor-se e destruir uma ordem injusta e irracional - baseada em privilégios e, segundo Hegel nos indica, contrária ao Direito - para, no seu lugar, instituir uma nova ordem política.

À violência para combater uma situação de injustiça, Hegel opõe a violência como sistema de governo. O momento do embate, da luta é, então, necessário - assim como na figura do senhor/servo é necessário que as consciências ponham sua vida em risco para superar seu estágio anterior, de ser como as coisas, para atingirem um patamar de ser como autoconsciência. Na Revolução Francesa, este momento de dissolução deve preceder uma nova ordenação, diferente da primeira, onde a Idéia de liberdade se efetive num sistema de leis e num Estado racional.

Ser contra toda ordem deve ser apenas um primeiro momento da liberdade que, ao manter-se e permanecer no tempo, tem como resultado o contrário de si, engendrando a tirania e o terror. Ao explicitar o primeiro momento lógico da vontade (a vontade da pura indeterminação), no $§ 5$ da Filosofia do Direito, Hegel nos dá dois exemplos de sua manifestação. Um primeiro encontrar-se-ia na religião, na forma do "fanatismo religioso da pura contemplação hindu". Este momento da vontade, quando se volta para o mundo, engendra um tipo de fazer político que "se traduz na destruição de toda ordem social existente e na expulsão de todo indivíduo suspeito de pretender uma ordem, assim como na aniquilação de toda ordem que queira ressurgir. Só destruindo algo tem esta vontade negativa o sentimento de sua existência". ${ }^{15}$

Há ai uma alusão clara a um dos momentos mais característicos do periodo do Terror: "a lei sobre os suspeitos" de 17 de setembro de 1793. Neste periodo, "os principios da nova ordem que queria ressurgir" - esboçados na "Declaração dos Direitos do Homem e do Cidadão" - perdem sua eficácia ao não dar origem a uma nova ordem que legisle universalmente sobre os indivíduos, sendo ao mesmo tempo expressão de sua vontade comum. $\mathrm{O}$ suspeito não o é frente a um conjunto de regras constituido

14 HEGEL Vorlesungen über die Philosophie der Geschichte ( $\mathrm{Ph}$. Gesch.), Werke in zwanzig Bänden, Moldenhauer/Michel, Suhrkamp Verlag, p. 258.

15 HEGEL, Grundlinien der Philosophie des Rechts (Ph. R.), Werke in zwanzig Bänden, Suhrkamp Verlag, § 5. 
pelos cidadãos - ele é suspeito frente ao Comitê de Salvação Pública, que toma para si a atividade de julgar enquanto uma atividade privada e não pública. $O$ indivíduo é considerado culpado, não por infringir normas constituídas, mas por parecer suspeito a alguns.

A relação entre a forma da liberdade característica da vontade indeterminada e o Terror é confirmada no Zusatz do próprio parágrafo 5 da Filosofia do Direito: "A ela corresponde, por exemplo, o periodo do Terror da Revolução, no qual se devia eliminar toda diferença baseada no talento ou na autoridade. Esta época estremecia ante toda particularidade, não podia suportá-la porque o fanatismo quer algo abstrato e não estruturado. Quando surgem diferenças, lhes opõe sua indeterminação e as elimina. Por isso o povo destruiu na Revolução as instituições que ele mesmo havia instaurado, porque para a autoconsciência abstrata toda instituição é contrária à igualda$\mathrm{de}^{\mathrm{II}}{ }^{16}$

Vemos ai o fio condutor que liga a vontade da pura indeterminação, tal como exposta na Filosofia do Direito, a autoconsciência abstrata da figura do senhor e do servo e um período específico da História. O Terror é, pois, para Hegel, um produto da vontade que - aos moldes da pura autoconsciência - se quer absolutamente livre, liberdade esta que não quer dar forma ao mundo. Por se pretender infinita e sem limitação, ela não pode causar a não ser destruição. O Terror conformaria, pois, um governo perpassado por esta fúria de destruição, cuja única obra é a morte, não deste ou daquele indivíduo, mas do próprio tecido social. A morte que visa somente a destruição, nos diz Hegel, é "a mais fria, a mais sem conteúdo, tão carente de significado quanto tomar um copo d'água". ${ }^{17}$

Surpreendemo-nos, ao menos à primeira vista, pelo fato de que esta sucessão de mortes que Hegel recrimina a propósito do Terror, não o faça quando se trata de guerras entre os Estados. Estas são consideradas como parte da relação entre eles, o que Hegel afirma aparentemente sem surpresa ou indignação. Deve-se notar que este autor, obviamente, não assistiu à brutalidade das guerras do século XX. Mesmo assim, visto que as guerras não oferecem jamais um espetáculo ameno, deve-se surpreender que aquele que julga que o Terror é a expressão da morte mais fria de todas, nos diga, por outro lado, que "as guerras modernas são levadas a cabo de um modo mais humano e as pessoas não se enfrentam entre si com ódio". ${ }^{18}$

Qual a diferença que poderia ser verificada entre o Terror e a Guerra e por que razão o primeiro - e não a segunda - pode ser considerado como um exemplo desta liberdade negativa que engendra destruição? Por que o enfrentar-se de dois Estados na guerra não nos remete também à luta de vida e morte? Por que apenas o Terror explicita, a nivel histórico, este senhor absoluto, a morte? Uma primeira resposta - que não deixa de ser insuficiente - seria: é a ausência de regras que determina a diferença. Na visão hegeliana, mesmo numa relação de guerra, o reconhecimento se mantém entre os Estados "o recíproco reconhecimento como tal dos Estados se mantém inclusive na guerra, na situação de falta de direito, de violência e contingência. Isto constitui um vínculo de forma que cada um dos Estados vale para outro como um existente em si e para si, de maneira tal que na guerra mesma a guerra se determina como algo

16 Ph. R., §5, Zusatz.

17 Ph. G., p. 436.

18 Ph. R., § 338, Zusatz. 
que deve ser passageiro"..$^{19}$ Este "dever ser passageiro" é o que confirmaria, aos olhos hegelianos, que a guerra não pretende instaurar-se enquanto um estado permanente de violência.

A morte do Terror, ao conträrio, é, antes de tudo, a morte do reconhecimento, pois aí as regras desaparecem e o que é esboçado como possibilidade de fundamento de alguma ordenação são princípios absolutamente subjetivos dos governantes. Um dos exemplos destes princípios era a virtude, tão exaltada por Robespierre como o fundamento da democracia. Assim se expressa no discurso pronunciado à Convenção Nacional em 4 de fevereiro de 1794: "Qual é o princípio fundamental do governo democrático ou popular, isto é, a mola essencial que o sustenta e o faz mover-se? É a virtude. Este sentimento sublime supõe a preferência do interesse público a todos os interesses particulares; de onde resulta que o amor da pátria supõe ainda ou produz todas as virtudes: pois o que serão estas senão a força da alma que torna estes sacrifícios possíveis? [...] Não somente a virtude é a alma da democracia, mas ela só pode existir neste governo". ${ }^{20}$

Para o Incorruptível, é este valor moral que fundamenta a República e é devido a ele apenas que os indivíduos podem colocar os interesses da coletividade acima dos interesses particulares. Para Hegel, a virtude de Robespierre carece de efetividade, ela não se traduz em princípios sólidos que possam fundamentar uma organização social. Ele não toma, no entanto, esta exaltação como um blefe, nem imputa a Robespierre estar utilizando a virtude como um belo invólucro para interesses escusos a ela. Ao contrário, é da natureza mesma da virtude não poder fornecer um caminho seguro à eticidade, por ser apenas "um princípio abstrato da liberdade, tal como se encontra na vontade subjetiva"..$^{21}$ A virtude nos dá apenas um terreno pantanoso que não pode ser mais do que abrigo da tirania. Diz-nos Hegel, nas Lições sobre a Filosofia da História: "Robespierre colocou o princípio da virtude como objeto supremo e pode-se dizer que este homem levou a virtude a sério. Pois agora a virtude e o terror dominam; com efeito, a virtude subjetiva, que reina apenas de acordo com o sentimento, traz com ela a mais terrivel tirania". ${ }^{22}$

Retomemos, então, a distinção que Hegel faz entre a morte do Terror e a morte da guerra: a primeira representaria a morte mesmo da possibilidade de organização social, enquanto a segunda dar-se-ia dentro de uma situação de reconhecimento entre os Estados. Esta distinção hegeliana torna-se ao menos embaraçosa se nos perguntarmos a quais guerras Hegel assiste no período de sua vida, isto é, de 1770 a 1831.

Embora Hegel não se referisse, necessariamente, na Filosofia do Direito apenas ao que assistiu, podemos supor que, para aquele que considerava que a leitura dos jornais era uma oração de todas as manhãs, os fatos de seu tempo estão em íntima vinculação com sua filosofia. Essencialmente, as guerras a que Hegel assiste são as batalhas napoleônicas, onde, pode-se dizer sem medo de injustiça, não se encontraria o suposto reconhecimento entre os Estados. Esta ausência da necessidade de reconhecimento é afirmada pelo próprio Napoleão por ocasião da paz de Campofórmio: "A República Francesa não necessita nenhum reconhecimento, assim como o Sol tam-
19 Ph. R., § 338.
20 Citado em TORRES, Figuras do Estado Modemo, São Paulo, Brasiliense, p. 474.
21 Ph. Gesch., p. 532.
22 Ph. Gesch., p. 533. 
pouco necessita que o reconheçam ${ }^{\text {n23 }}$ Para Hegel, esta afirmação é apenas uma força de expressão e contém em si a existência do reconhecimento, ainda que não explícito.

Ora, este comentário carece de força explicativa, pois obviamente não se verifica, na formação do Império napoleônico, o respeito para com os outros Estados, respeito este que é condição necessária do reconhecimento, já que "o reconhecimento exige a garantia de que reconheça, por sua vez, aos Estados que o reconhecem, isto é, que os respeitem em sua independência". ${ }^{24}$

Se o reconhecimento à República Francesa está implícito nos dizeres de Napoleão, pode-se dizer que o contrário não se verifica: a França napoleônica não reconhece como Estados aqueles que a reconhecem. Deve-se, então, perguntar: por que este reconhecimento unilateral não engendra destruição? Por que Napoleão não pode ser tomado como um exemplo de consciência que arrisca sua própria vida em busca de uma autonomia que prescinda do reconhecimento? Há duas razões, centralmente, para tal. Primeira, a ausência da necessidade do reconhecimento se justificaria à medida que as outras nações se distanciam bastante da idéia hegeliana de Estado. Segundo, porque enquanto as consciências que entram na luta de vida e morte são um exemplo da vontade que não quer nenhuma limitação, Napoleão expressa, ao contrário, a ordenação estável dos princípio da Revolução Francesa. Analisemos, pois, com mais detalhe estes dois argumentos.

Se a Revolução Francesa traz ao mundo uma nova etapa da história política humana e os princípios da constituição de um Estado racional, a Prússia, a Áustria, a Itália, por outro lado, eram nações fragmentadas, com um poder central enfraquecido e com resquícios ainda de uma organização feudal. Segundo Hegel, as campanhas napoleônicas levam a estas nações, não a destruição ou a opressão, mas uma nova forma de organização política.

Com a vitória da batalha de Iena em 1806, encerra-se o Sacro Império Romano Germânico, fundado em 800 d.C. por Carlos Magno. A queda de um império de mais de 1.000 anos não causa indignação e sim uma profunda admiração de Hegel pela figura napoleônica. Se alguns consideram que Napoleão personifica a derrota dos ideais da Revolução Francesa, para Hegel ele é a possibilidade mesma de extensão destes ideais por todos os cantos da Europa.

Hegel será fiel à sua admiração, mesmo após a morte de Napoleão. Este, ao lado de César e Alexandre, é descrito nas Lições sobre a Filosofia da História como um herói: os "homens de negócio do Espírito do mundo", cujos atos e discursos "são o que há de melhor no seu tempo", pois eles sabem aquilo que é necessário, aquilo para o qual é chegada a hora (was nicht und was an der Zeit ist)". ${ }^{25}$

E o que urgia era a necessidade de ultrapassar a virtude e o terror como princípios da relação entre os homens: "Ela [a virtude] exerce sua potência sem usar as formas jurídicas e a punição que ela infringe é também simples: a morte. Esta tirania necessitava acabar, pois todas as inclinações, todos os interesses, a razão mesma se opunha a esta terrivel liberdade conseqüente que, na sua concentração, entrou em cena de uma maneira tão fanática. Novamente se apresenta um governo organizado,

23 Citado em Ph. R., § 331, Zusatz.

24 Ph. R., § 331.

25 Ph. Gesch., p. 46. 
como o antigo, somente o chefe e o monarca são agora um diretório variável de cinco membros, formando, sem dúvida, uma unidade moral mas não individual. A desconfiança também reinava entre eles e o governo estava nas mãos das assembléias legislativas; ele teve o mesmo destino fatal, pois a necessidade absoluta de uma potência governamental se fazia sentir. [...] Napoleão se colocou novamente na cabeça do Estado como vontade individual [...]. Ele dirigiu ao exterior o imenso poder de seu caráter, submeteu toda a Europa e espalhou por todos os lados suas instituições liberais". ${ }^{26}$

Napoleão supera a vontade infinita que, na sua recusa de toda determinação, engendra apenas a destruição de tudo que é fixo. Ele representa a volta das autoconsciências a um projeto de ordenação. Estas, através do temor da morte, isto é, do medo da destruição de toda ordem social, retornam à efetividade. A ordem que deve ser criada não é a mesma ordem que a Revolução Francesa colocou por terra. O que Hegel assinala através do seu elogio constante a Napoleão é que a negação de uma realidade deve conduzir a uma nova efetividade, superando o período da negação abstrata, daquela vontade que não se limita a destruir o antigo, mas se opõe também ao novo que quer edificar-se enquanto ordenação. Como bem nota Hyppolite: "Napoleão deu a Hegel o sentimento do Estado moderno, da mesma forma que a Prússia tentará constituí-lo. Mas se o espírito objetivo não é absolutamente idêntico ao espírito objetivo que o precedeu, o princípio é, no entanto, o mesmo; é necessário voltar a um espírito objetivo, a uma vontade geral que renuncia a si mesmo, fazendo-se substância no elemento do ser". ${ }^{27}$

Retomando, então, nossa analogia, podemos dizer que, enquanto o Terror personifica a morte do reconhecimento, por sua vez, a morte imposta aos adversários nas guerras napoleônicas não significa a impossibilidade de uma situação de reconhecimento, mesmo que Napoleão não reconheça as outras nações como Estados. Ao contrário, Napoleão, na visão de Hegel, através de suas campanhas leva o novo princípio de organização social a outros povos a fim de que eles também se constituam enquanto Estados racionais, para que eles também possam constituir uma realidade sócio-política baseada no reconhecimento do outro, Poder-se-ia, então, dizer que - aos moldes da consciência trabalhadora que ao final da figura aponta um caminho para a formação do mundo - Napoleão informa o mundo, divulgando os princípios de um Estado que efetiva os ideais da Revolução Francesa.

Qual o sentido, então, da morte que aparece como impossibilidade na figura do senhor e do servo? Segundo a análise feita, a morte da qual nos fala o texto em questão é a morte do reconhecimento, e esta morte é a destruição da possibilidade da construção do Estado no seu sentido hegeliano, isto é, "a efetivação da Idéia Ética", no qual "o indivíduo tem sua liberdade substancial como sua essência, fim e produto de sua atividade". ${ }^{28}$

Afasto-me, pois, da concepção de alguns comentadores da obra hegeliana, como Kojève, que vê na experiência do medo da morte o enfrentar-se do homem com sua

Ph. Gesch., p. 533.

HYPPOLITE, Genèse et Structure de la Phénoménologie de l'Esprit de Hegel, Paris, Aubier, tomo 2, p. 447.

Ph. R., § 257. 
finitude..$^{29}$ Esta me parece atribuir a Hegel uma nuance próxima da analítica existencial, atribuição a meu ver, equivocada, já que Hegel não ancora sua filosofia no finito e sim no infinito, não no homem enquanto indivíduo particular, mas no Espírito enquanto expressão do Absoluto no mundo propriamente humano. A finitude pareceme, portanto, fazer parte do percurso mesmo do Espirito e representar a morte possível, que o integra: "Não é esta vida que recua diante da morte e se preserva pura da destruição, mas a vida que traz em si a morte, e se mantém na morte mesma, que é a vida do Espirito" ${ }^{30} \mathrm{O}$ percurso do Espírito não desiste frente à finitude ou à imperfeição do ser finito, mas o supera e disto provém sua potência: "o Espírito é esta potência somente em saber olhar o negativo de frente e em saber permanecer junto dele". ${ }^{31}$

A morte impossivel é, ao contrário, aquela que não pode ser encarada pelo Espírito, pois representa o extermínio da vida, a impossibilidade da relação entre os homens e, portanto, a aniquilação do percurso mesmo do Espírito. É esta possibilidade de negativo absoluto que os homens temem e seu horror a este Senhor Absoluto é o que os faz construir e manter a civilização.

29 Ver o capítulo 'L'idée de la mort dans las philosophie de Hegel, In KOJÈVE, op. cit.

30 Ph. G., p. 36.

31 Ph. G., p. 36. 